\title{
Coarsening of carbon black supported Pt nanoparticles in hydrogen
}

\author{
Simonsen, Søren Bredmose ; Wang, Yan; Jensen, Jens Oluf; Zhang, Wenjing (Angela)
}

Published in:

Nanotechnology

Link to article, DOI:

10.1088/1361-6528/aa91a8

Publication date:

2017

Document Version

Peer reviewed version

Link back to DTU Orbit

Citation (APA):

Simonsen, S. B., Wang, Y., Jensen, J. O., \& Zhang, W. (2017). Coarsening of carbon black supported Pt nanoparticles in hydrogen. Nanotechnology, 28(47), [475710]. https://doi.org/10.1088/1361-6528/aa91a8

\section{General rights}

Copyright and moral rights for the publications made accessible in the public portal are retained by the authors and/or other copyright owners and it is a condition of accessing publications that users recognise and abide by the legal requirements associated with these rights.

- Users may download and print one copy of any publication from the public portal for the purpose of private study or research.

- You may not further distribute the material or use it for any profit-making activity or commercial gain

- You may freely distribute the URL identifying the publication in the public portal

If you believe that this document breaches copyright please contact us providing details, and we will remove access to the work immediately and investigate your claim 
ACCEPTED MANUSCRIPT

\section{Coarsening of carbon black supported Pt nanoparticles in hydrogen}

To cite this article before publication: Søren Bredmose Bredmose Simonsen et al 2017 Nanotechnology in press https://doi.org/10.1088/1361$\underline{6528 / a a 91 a 8}$

\section{Manuscript version: Accepted Manuscript}

Accepted Manuscript is "the version of the article accepted for publication including all changes made as a result of the peer review process, and which may also include the addition to the article by IOP Publishing of a header, an article ID, a cover sheet and/or an 'Accepted Manuscript' watermark, but excluding any other editing, typesetting or other changes made by IOP Publishing and/or its licensors"

This Accepted Manuscript is () 2017 IOP Publishing Ltd.

During the embargo period (the 12 month period from the publication of the Version of Record of this article), the Accepted Manuscript is fully protected by copyright and cannot be reused or reposted elsewhere.

As the Version of Record of this article is going to be / has been published on a subscription basis, this Accepted Manuscript is available for reuse under a CC BY-NC-ND 3.0 licence after the 12 month embargo period.

After the embargo period, everyone is permitted to use copy and redistribute this article for non-commercial purposes only, provided that they adhere to all the terms of the licence https://creativecommons.org/licences/by-nc-nd/3.0

Although reasonable endeavours have been taken to obtain all necessary permissions from third parties to include their copyrighted content within this article, their full citation and copyright line may not be present in this Accepted Manuscript version. Before using any content from this article, please refer to the Version of Record on IOPscience once published for full citation and copyright details, as permissions will likely be required. All third party content is fully copyright protected, unless specifically stated otherwise in the figure caption in the Version of Record.

View the article online for updates and enhancements. 


\title{
Coarsening of carbon black supported Pt nanoparticles in hydrogen
}

\author{
Søren Bredmose Simonsen ${ }^{a}$, Yan Wang ${ }^{b}$, Jens Oluf Jensen ${ }^{a}$, Wenjing Zhang ${ }^{a}$ \\ ${ }^{a}$ Department of Energy Conversion and Storage, Technical University of Denmark, DK-4000 Roskilde, Denmark \\ ${ }^{b}$ Department of Chemical Engineering, Huaihai Institution of Technology, 222005 Lianyungang City, China \\ Corresponding author: Sфren B. Simonsen,e-mail: sobrs@dtu.dk \\ Second corresponding author: Wenjing Zhang,e-mail:wenz@dtu.dk
}

\begin{abstract}
This study addresses coarsening mechanisms of Pt nanoparticles supported on carbon black in hydrogen. By means of in situ transmission electron microscopy (TEM), Pt nanoparticle coarsening was monitored in 6 mbar $20 \% \mathrm{H}_{2} /$ Ar while ramping up the temperature to almost $1000{ }^{\circ} \mathrm{C}$. Time-resolved TEM images directly reveal that separated ca. $3 \mathrm{~nm}$ sized Pt nanoparticles in a hydrogen environment are stable up to ca. $800{ }^{\circ} \mathrm{C}$ at a heating rate of $10{ }^{\circ} \mathrm{C} / \mathrm{min}$. The coarsening above this temperature is dominated by the particle migration and coalescence mechanism. However, for agglomerated Pt nanoparticles, coalescence events were observed already above $200{ }^{\circ} \mathrm{C}$. The temperature-dependency of particle sizes and the observed migration distances are described and found to be consistent with simple early models for the migration and coalescence.
\end{abstract}

\section{Introduction}

The control of sizes and shapes of nanostructures is of tremendous importance in a wide field of applications such as nanoelectronics, optics, electrochemistry and catalysis [1-4]. The use of nanoparticles in catalysis is for example a way of getting the most active surface area from the often expensive catalytic materials [1]. However, nanostructures often sinter to form coarser and more stable structures that may not have the intended physicochemical properties [5]. To advance synthesis methods for more stable nanostructures, it is crucial to understand the relevant coarsening mechanisms and parameters that influence the coarsening process.

One mechanism for nanoparticle coarsening is Ostwald ripening where mass is transported by migration of atomic species between immobile nanoparticles [5,6]. An atom at one of the surface crystal planes of a particle, or so-called adatom, may escape the particle to the support material and migrate to another particle where it is adsorbed [6].

A different mechanism is particle migration and coalescence, where entire nanoparticles migrate randomly at the support surface followed by coalescence between migrating particles. Migration of entire particles is explained by thermally activated atom diffusion at the particle surfaces. Accumulation of diffusing atoms on one side of the particle will slightly shift the particle center and thereby lead to Brownian motion [6]. By considering nonwetting spherical particles, the following relation between the particle diffusivity, $D_{p}$, the surface diffusion coefficient, $D_{s}$, atom diameter, $a$ and particle radius, $R$ has been suggested [6]: 


$$
D_{p}=0.3 D_{s}\left(\frac{a}{n}\right)^{4}
$$

By using eq. 1, it can be shown that at isothermal conditions the average particle migration distance $X_{p}$, for randomly migrating particles is equal to [6]:

$$
\left.X_{p}=\sqrt{4 D_{p} t}=\frac{\sqrt{1.2 D_{g} a^{4} t}}{R^{2}}, \quad \text { (eq. } 2\right)
$$

where $t$ is time. The surface diffusion coefficient, $D_{s}$ depends via the Arrhenius equation exponentially on temperature [7]:

$$
D_{s}=D_{0} \exp \left(\frac{-E_{\pi}}{k T}\right), \quad(\text { eq. } 3)
$$

where $D_{0}$ is a pre-exponential factor, $E_{a}$ the activation energy for self-diffusion, $k$ Boltzmann's constant and $T$ the temperature. To illustrate the strong dependence of particle size on $X_{p}$, values for $E_{a}$ and $D_{0}$ for a Pt surface (2.89 eV and $0.22 \mathrm{~cm}^{2} / \mathrm{s}$ from reference [7]) are inserted and presented in Figure 1a. The figure shows a strong dependence on $X_{p}$ from both temperature and the particle size.

A coalescence event is characterized by three steps 1) neck growth, 2) neck elimination and 3) complete coalescence to form the equilibrium particle shape. An early kinetic model describes the duration time, $\tau$ of each step [6]:

where $R_{0}$ is the initial particle radius, $c=2.92 \cdot 10^{-5}$ for neck growth, $c=0.166$ for neck elimination, $c=0.89$ for complete coalescence and $B$ is:

$$
B=\frac{D_{g} N_{Q} Y_{0} \Omega^{2}}{k T},
$$

where $N_{0}$ is the average density of surface sites on the particle, $\gamma_{0}$ the average surface energy and $\Omega$ the atomic volume. To illustrate the difference in temperature dependence for the coalescence steps, Figure $1 \mathrm{~b}$ presents $\tau$ for 
the steps 1-3 of a coalescence event for Pt nanoparticles with a diameter $=3 \mathrm{~nm}$. It can be seen that neck growth (dotted red line) is a rapid process compared to neck elimination (dashed red line) and complete coalescence (full red line). The figure also compares $\tau$ for coalescence (red lines) with the duration time for an average migration distance, $X_{p}=1 \mathrm{~nm}$ (blue line) for Pt nanoparticles with diameters $=3 \mathrm{~nm}$. The figure illustrates that coalescence is generally a faster process that can be initiated and completed at lower temperatures compared to particle migration for identically sized particles. It should be noted that, the reported values for $E_{a}$ and $D_{0}$ differ significantly [7-11], and possible effects of the gas environment and the support material is not taken into account in the models presented in Figure 1.

Pt is known to be a very active catalyst in several chemical reactions both in oxidizing and reducing environments. For example, carbon supported Pt nanoparticles are used as a catalyst in fuel cells $[13,14]$. Coarsening of supported $\mathrm{Pt}$ nanoparticles can take place in the reactive conditions or during high temperature pre-treatment as part of the catalyst synthesis [15].

Both Ostwald ripening and particle migration/coalescence has been reported for Pt nanoparticles supported on amorphous carbon in vacuum [9]. However, the gas environment can highly influence the degree of coarsening and possibly also which coarsening mechanism that will dominate [16,17]. In an oxidizing environment, increasing metal dispersions are often reported for supported Pt nanoparticles at temperatures near $500{ }^{\circ} \mathrm{C}$ $[5,16,18,19]$, while at higher temperatures $\mathrm{O}_{2}$ enhance coarsening compared with $\mathrm{H}_{2}, \mathrm{~N}_{2}$, Ar or vacuum $[5,16,17$, 20,21]. Recent studies have shown that coarsening of oxide supported Pt nanoparticles in oxygen is fully dominated by Ostwald ripening [22,23]. It is suggested that $\mathrm{O}_{2}$ enhance Ostwald ripening by formation of volatile Pt-oxygen species [24]. Similarly, an STM study showed that volatile Pt-hydrogen species form at Pt surfaces in $\mathrm{H}_{2}$ environment to increase surface diffusion [25]. It is, however, not known whether the increased surface diffusion by $\mathrm{H}_{2}$ also leads to Ostwald ripening or, by increasing the value of $D_{s}$ in eq. 2 , to particle migration. A few studies have addressed the coarsening mechanism for supported Pt nanoparticles in $\mathrm{H}_{2}$, but conclude that Ostwald ripening and particle migration/coalescence cannot be distinguished from the data $[21,26]$. One study of $\mathrm{Pt}$ nanoparticles supported on $\mathrm{Al}_{2} \mathrm{O}_{3}$ in $\mathrm{H}_{2}$ concludes that particle migration and coalescence dominates based on observation of a log-normal type shape of the particle size distribution after coarsening [27]. Indeed, early studies have suggested that particle size distributions after particle migration/coalescence will have a log-normal type shape, while the distribution after Ostwald ripening can be statistically described by the so-called LSW model from Lifshitz and Slyozov [28] and Wagner [29]. However, the method of using the shape of particles size distributions to determine coarsening mechanism has been debated [30-32] and it has recently been shown that the shape of particle size distributions depend not only on the coarsening mechanism, but also on the morphology of the supported Pt nanoparticles [33]. Coarsening mechanisms can on the other hand be distinguished by using microscopy methods that allow for observations of the individual nanoparticles during heat treatment in the relevant gas environment. Several such in situ studies have successfully described nanoparticle coarsening mechanisms for different metals and gas environments by using scanning tunneling microscopy (STM) [34-36], low-energy electron microscopy (LEEM) [37] and transmission electron microscopy (TEM) [38-43].

In this study we use in situ TEM to monitor the coarsening of Pt nanoparticles supported on carbon black (CB) at elevated temperatures in $\mathrm{H}_{2}$. In situ TEM image series directly reveal the dominating coarsening mechanism and we compare the experimental observations with theoretical models. Furthermore, the present $\mathrm{Pt} / \mathrm{CB}$ catalyst 
contains two types of Pt nanoparticles; agglomerated and separated. The image analysis allows for a detailed comparison of the two types of Pt while ensuring the same coarsening conditions for both types.

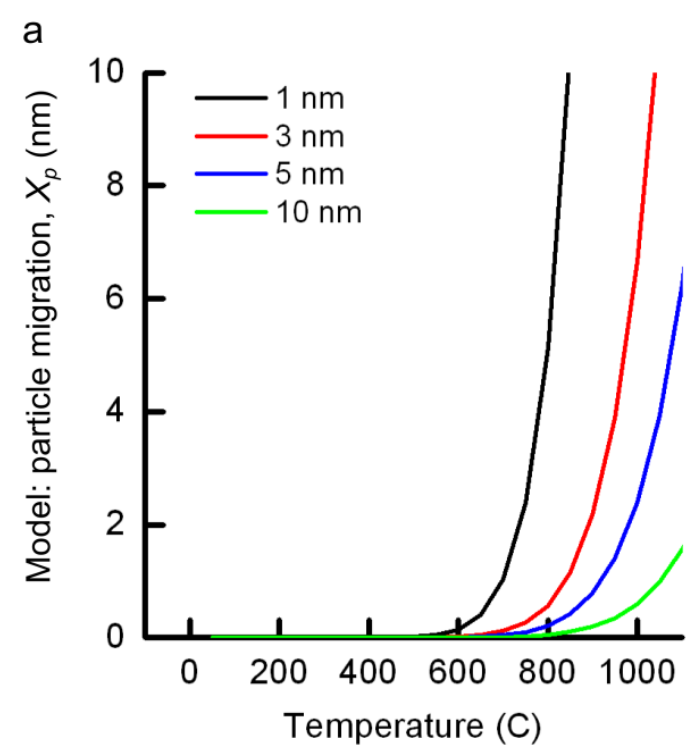

$\mathrm{b}$

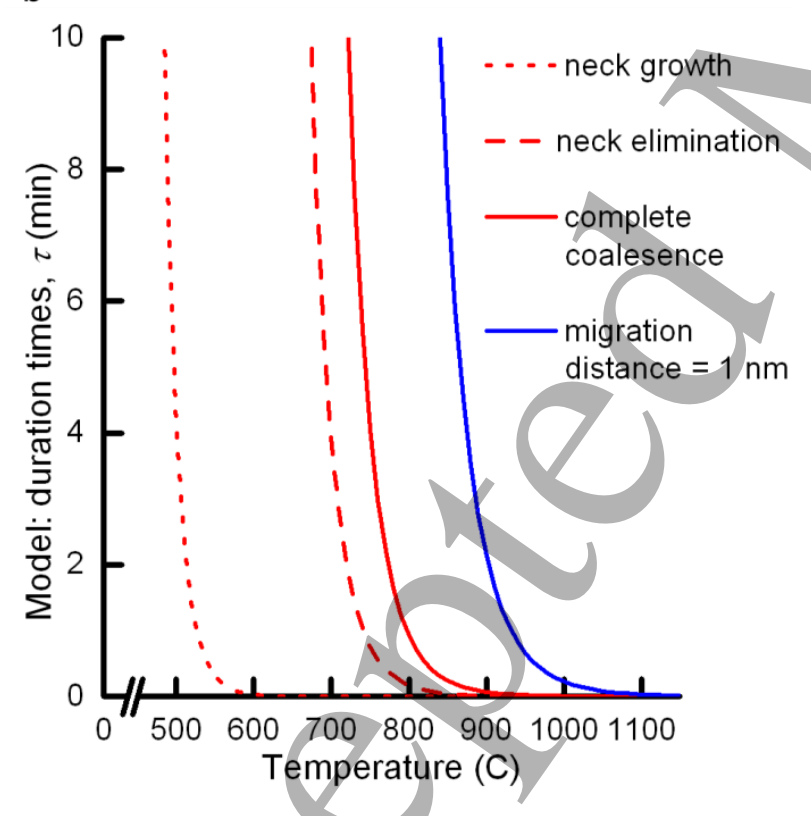

Figure 1. (a) Calculated average Pt nanoparticle migration distances, $X_{p}$ as a function of temperature for four diameters indicated in the figure and a coarsening time, $t=10 \mathrm{~min}$. The figure is calculated from eqs. $2-4$ using $E_{a}=2.89 \mathrm{eV}$ and $D_{0}=0.22 \mathrm{~cm}^{2} / \mathrm{s}$ from reference [7]. (b) Calculated duration for a coalescence event (eq. 4-5) and for migration (eq. 1-3) as a function of temperature for Pt particles with a diameter $=3 \mathrm{~nm}, Y_{0}=3.28 \mathrm{eV} / \mathrm{nm}^{2}$ from reference [12]. The duration times, $\tau$ for neck growth (dotted), neck elimination (dashed) and complete 
coalescence (full) are presented by red lines. The time for migration for an average migration distance, $X_{p}=1$ $\mathrm{nm}$ is presented by a blue line.

\section{Experimental}

In situ TEM experiments were performed using a Titan 80-300 (FEI) electron microscope equipped with a differentially pumped environmental cell [44] operated at $300 \mathrm{keV}$. Heating was facilitated by a heating holder from DENS solutions which is a chip based heating holder with temperature feedback based on a 4-point-probe resistive measurement of the micro hotplate. The holder was plasma cleaned for $10 \mathrm{~min}$ before mounting the chip with the Pt/CB sample. The Pt/CB catalyst was HiSPEC 9100 purchased from Johnson Matthey, composed of 55.5 to $58.5 \mathrm{wt} \% \mathrm{Pt}$ on high surface area carbon support. The Pt-CB was suspended in ethanol (99.9\% purity) and agitated in an ultrasonic bath. A drop of the suspension was placed on the thermal chip followed by drying at $60{ }^{\circ} \mathrm{C}$ on a hot plate. The in situ experiment was performed by exposing the sample to $6 \mathrm{mbar} 20 \% \mathrm{H}_{2} / \mathrm{Ar}$ while constantly ramping the temperature by $10{ }^{\circ} \mathrm{C} / \mathrm{min}$ and recording TEM images with $2 \mathrm{~s}$ total exposure time by summing and cross correlating 31 frames for each image by using a OneView camera (Gatan company). Another in situ TEM experiment were conducted for Pt/CB mixed with Polyvinylpyrrolidone (PVP) and electrospun into a nanofiber. The same $\mathrm{H}_{2} / \mathrm{Ar}$ gas composition and pressure as well as temperature ramping rate was applied. Since $\mathrm{Ar}$ is an inert gas, we do not consider it to have any important influence on the results presented in the following. The only reason for adding Ar was to make the experimental conditions directly comparable to results from a different study which is not reported here.

From the TEM images, all Pt nanoparticle sizes were measured by manually outlining the particle edges using the software ImageJ. Particle diameters were calculated by using a circular approximation to their measured projected area. It should be noted that Pt nanoparticles that are agglomerated with other Pt nanoparticles often show projected shapes that deviate more from a circle than those of the individual Pt nanoparticle at the CB support. The estimated measuring error for the diameter is $\pm 0.2 \mathrm{~nm}$ for individual Pt nanoparticles and $\pm 0.4 \mathrm{~nm}$ for agglomerated Pt nanoparticles. The particle migration was measured manually by firstly aligning the position of the $\mathrm{CB}$ support in each frame to minimize the $\mathrm{CB}$ movement and secondly by estimating the centers of the $\mathrm{Pt}$ nanoparticles in each frame and calculating the projected particle displacement from the first frame. An error of ca $1 \mathrm{~nm}$ is estimated for projected particle migration measurements.

To make sure that the observed dynamics were not dominated by artefacts induced by the electron beam, which had a beam current density of ca. $8000 \mathrm{e} / \mathrm{nm}^{2} \mathrm{~s}$, TEM images of sample regions monitored over the prolonged periods of the in situ experiment, were acquired only every fifth minute and the electron beam was removed from the region in the time between image acquisitions. During and after the experiment, regions monitored during the experiment were compared with regions that were previously unexposed to the electron beam. Similar $\mathrm{Pt} / \mathrm{CB}$ structures were found in both types of regions. It is therefore concluded that the influence of the electron beam is not dominating the dynamics presented in this study. 


\section{Results and discussion}

Figure 2 presents an in situ TEM image series of the Pt/CB catalyst during temperature ramping at $10{ }^{\circ} \mathrm{C} / \mathrm{min}$ from $50{ }^{\circ} \mathrm{C}$ to $960{ }^{\circ} \mathrm{C}$ in 6 mbar of $20 \% \mathrm{H}_{2} / \mathrm{Ar}$ (a movie of the full images series is available in the supplementary information). Due to mass-thickness contrast, the Pt nanoparticles can be observed as small dark and almost circular areas on the larger and lighter grey $\mathrm{CB}$ particles. The smaller Pt particles scatter electrons less than the larger ones and therefore show lower contrast. The image contrast also depends on the focus settings which vary through the image series. The size and position of the smallest particles can therefore be difficult to follow in the image series. However, a number of particles with initial diameters around $3 \mathrm{~nm}$ can be followed as a function of temperature in the image series.
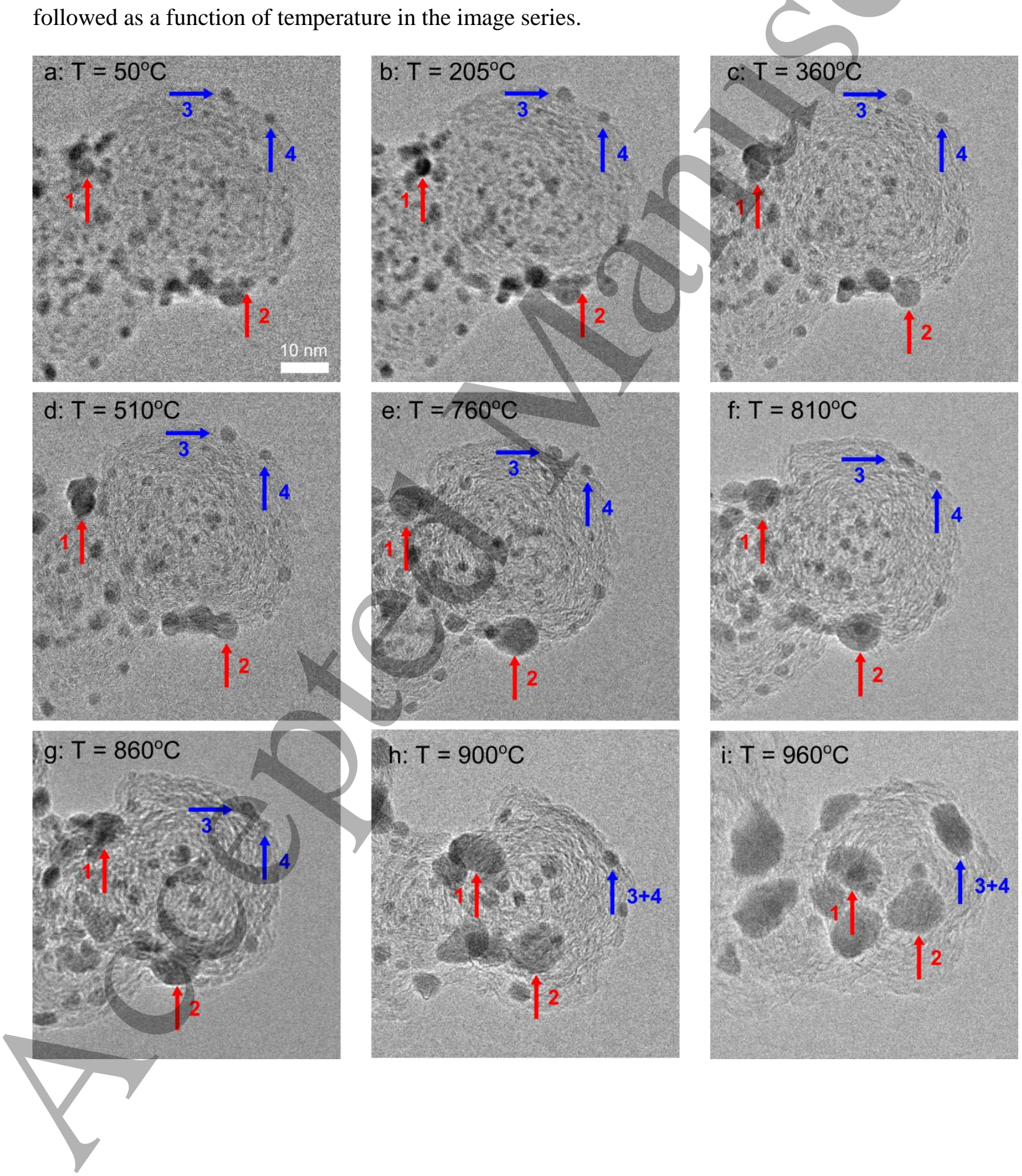
Figure 2. (a-i) In situ TEM images of Pt nanoparticles on a CB support during temperature ramping at $10^{\circ} \mathrm{C} / \mathrm{min}$ and exposure of $6 \mathrm{mbar} 20 \% \mathrm{H}_{2} / \mathrm{Ar}$. Temperatures are indicated in the images. Examples of two types of $\mathrm{Pt}$ nanoparticles are indicated by arrows: agglomerated (red) and separated (blue).

Two types of Pt nanoparticles can be identified: Pt nanoparticles in agglomerates of Pt nanoparticles (for example particle no. 1 and 2 in Figure 2) and $\mathrm{Pt}$ nanoparticles that appear to be physically separated from other $\mathrm{Pt}$ nanoparticles and only have physical contact to the support (for example particle no. 3 and 4 in Figure 2). According to the figure, the separated Pt nanoparticles are stable up to ca. $800{ }^{\circ} \mathrm{C}$ during the time of the experiment (See for example particles no. 3 and 4 in Figure 2a-f). At higher temperatures the separated particles migrate and coalesce with other Pt particles (See for example particles no. 3 and 4 in Figure 2f-i). Contrary to this, the agglomerated Pt nanoparticles grow in size by coalescence with their neighbor Pt nanoparticles in the agglomerate at much lower temperatures (See for example particles no. 1 and 2 in Figure $2 b-c$ ). The coalescence process for particles 1 and 2 can be seen in more detail in the movie available in the supplementary information. Recent studies have shown that coalescence of Pt nanoparticle can be induced by the electron beam [22], and therefore it cannot be excluded that some of the observed coalescence events are at least partly induced by the electron beam. Images of regions that were previously unexposed to the electron beam, however, also showed that agglomerated Pt nanoparticles had coalesced, and that to a degree that was comparable to the regions that were exposed to the electron beam several times during the experiment. We therefore conclude that the observed coalescence of the agglomerated Pt nanoparticles is not dominated by effects of the electron beam.

More and lager regions than the one presented in Figure 2 were observed and the behavior of the separated and agglomerated particles are representative for all the monitored areas. Also, the additional in situ TEM experiment performed for Pt/CB mixed with PVP electrospun into a nanofiber show the same trends as presented by Figure 2. Also for these samples, the separated $\mathrm{Pt}$ nanoparticles are stable up to ca. $800{ }^{\circ} \mathrm{C}$ during the time of the experiment and agglomerated Pt nanoparticles grow by coalescence with their neighbor Pt nanoparticles at lower temperatures.

The diameters of the four particles no. 1-4 in Figure 2 are presented as a function of temperature for the full images series in Figure 3a. The two separated Pt nanoparticles (no. 3 and 4) have stable diameters up to temperatures slightly higher than $800{ }^{\circ} \mathrm{C}$. The two particles coalesce at $900{ }^{\circ} \mathrm{C}$ (Figure $2 \mathrm{~h}$ and Figure 3a). Until this coalescence event, no continuous growth or shrinkage is observed for the separated Pt nanoparticles. The inset in Figure $3 \mathrm{a}$ (blue) presents measured diameters for 8 additional randomly selected separated Pt nanoparticles and shows the same trend as observed for particle no. 3 and 4: no continuous shrinkage or growth is observed for the separated $\mathrm{Pt}$ nanoparticles and growth is only observed as coalescence events at temperatures above $800{ }^{\circ} \mathrm{C}$. These results show that the coarsening of Pt nanoparticles supported on $\mathrm{CB}$ is fully dominated by the migration and coalescence mechanism when exposed to $\mathrm{H}_{2}$. The Ostwald ripening mechanism does not appear to play any role in this enyironment. These observations are contrary to the coarsening of supported $\mathrm{Pt}$ nanoparticles in an oxidizing environment which is fully dominated by Ostwald ripening [22,23]. This result indicates that although the surface self-diffusion of $\mathrm{Pt}$ atoms has been reported to be enhanced by $\mathrm{H}_{2}$ [25], the Pthydrogen species are not escaping the Pt surface for atomic diffusion at the support. For carbon supported Pt nanoparticles in vacuum, a recent study concludes that coarsening is dominated by both Ostwald ripening and particle migration [9]. This could suggest that the presence of $\mathrm{H}_{2}$ enhances particle migration or represses Ostwald ripening, but a careful comparison between the two environments $\left(\mathrm{H}_{2}\right.$ and vacuum) with otherwise identical experimental conditions will be necessary to fully support such conclusions. 
The diameters of the agglomerated Pt nanoparticles increases in steps (particle no. 1 and 2 in Figure 3a) which is a typical growth pattern for individual nanoparticles that are coarsening by a coalescence mechanism [45]. This is because a coalescence event involves addition of many atoms to the particles in one step, contrary to an Ostwald ripening mechanism where growth of individual particles are characterized by smoother growth (or shrinkage) curve due to a continuous net addition (or loss) of atoms [22,23,34]. After each rapid increase in size, the diameters of particle no. 1 and 2 are relatively stable. Some variation in particle size is observed directly after the rapid increase which is a result the complete coalescence step where the equilibrium particle shape is formed. The inset in Figure 3a (red) shows that the step-wise growth at lower temperatures observed for particle no. 1 and 2 is a general trend for the agglomerated Pt nanoparticles. The agglomerated Pt particles are clearly less stable than the separated particles. This is also illustrated by Figure $3 \mathrm{~b}$ presenting the mean particle diameter for 10 agglomerated (red) and separated (blue) Pt nanoparticles. The agglomerated Pt particles start to coarsen at temperatures above $200{ }^{\circ} \mathrm{C}$ while separated particles as mentioned, start to coarsen at ca. $800{ }^{\circ} \mathrm{C}$. It is important to note that this large difference in coarsening onset temperature for separated and agglomerated $\mathrm{Pt}$ particle cannot be explained by differences in the experimental conditions. It should also be noted that the initial particle sizes are approximately identical for the two types of Pt nanoparticles (Figure 3a-b). These observations are consistent with theoretical models which describe that for identically sized particles the three steps of coalescence can occur at lower temperatures compared to particle migration, as shown in Figure $1 \mathrm{~b}$. 

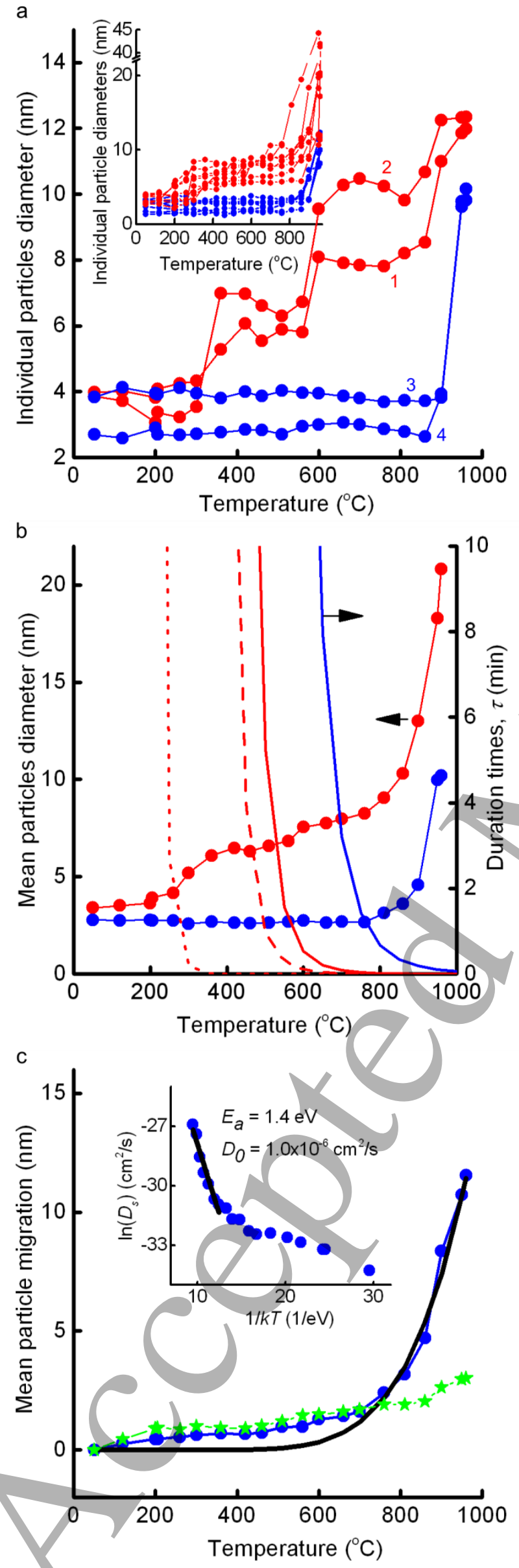
Figure 3. (a) Measured diameters of the agglomerated (red) and separated (blue) particles indicated in

Figure 2 presented as a function of temperature. Inset: Measured diameters for additional 8 separated and 8 agglomerated Pt nanoparticles. (b) The measured mean diameter of 10 particles of each type: agglomerated particles (red) and separated particles (blue). For comparison with the theoretical model presented in Figure 1b, the model is re-plotted now using the experimental $E_{a}, D_{0}$ values obtained from the Arrhenius analysis in (c). (c) The measured average apparent particle migration distance, $X_{p}$ relative to their starting position at $50{ }^{\circ} \mathrm{C}$ as a function of temperature for 10 separated Pt particles (blue). The motion of the CB support, measured as the mean displacement for three different points at the $\mathrm{CB}$ surface relative to their starting position at $50 /{ }^{\circ} \mathrm{C}$, is presented by green stars. For comparison, the model for $X_{p}$ (Figure 1a) is shown now with experimental values for $E_{a}, D_{0}$ from the Arrhenius analysis, $R=1.5 \mathrm{~nm}, \mathrm{a}=0.25 \mathrm{~nm}$ and $\mathrm{t}=10 \mathrm{~min}$ (black line). Inset: Arrhenius analysis with a linear fit (black line) to the data (blue) for $T=760-950{ }^{\circ} \mathrm{C}$. The apparent activation energy, $E_{a}$ and pre-factor, $D_{0}$ is indicated in the figure.

The apparent particle migration distance was measured for 10 randomly selected separated Pt particles and the average apparent particle migration distance, $X_{p}$ is presented as a function of temperature in Figure $3 c$ (blue). We call it the apparent migration distance because TEM image are $2 \mathrm{D}$ projections of $3 \mathrm{D}$ objects and the $\mathrm{Pt}$ nanoparticle motion is therefore only presented in two dimensions. This means that the measured migration distance will always be smaller than or equal to the real migration distance. For comparison the motion of the $\mathrm{CB}$ support is shown Figure 3c (green stars). The presented CB support motion is the mean value of the apparent migration distance for three randomly chosen points at the $\mathrm{CB}$ surface. The slight increase in $X_{p}$ for the $\mathrm{Pt}$ nanoparticles (from 0 to $1.3 \mathrm{~nm}$ ) in the temperature interval from $50^{\circ} \mathrm{C}$ to ca. $660{ }^{\circ} \mathrm{C}$ can be explained by small movements of the $\mathrm{CB}$ support since the alignment of the position of the $\mathrm{CB}$ support in the images was not perfect. For example small rotational movements could not be perfectly compensated for. Figure $3 \mathrm{c}$ therefore shows that particle migration of $\mathrm{CB}$ supported $\mathrm{Pt}$ nanoparticle with a diameter of ca. $3 \mathrm{~nm}$ in $\mathrm{H}_{2}$ is initiated at ca. $800{ }^{\circ} \mathrm{C}$. This observation is consistent with Figure $3 \mathrm{~b}$ which indirectly suggests that migration takes place above $T=800$ ${ }^{\circ} \mathrm{C}$ in order to allow for coalescence of the separated Pt nanoparticles.

To further compare the theoretical models with the experimental measurements, an Arrhenius analysis was performed (inset in Figure 3c). A straight line (black) is fitted to the data in the high temperature range $\left(760{ }^{\circ} \mathrm{C}\right.$ $950{ }^{\circ} \mathrm{C}$ ) where actual $\mathrm{Pt}$ migration is observed, giving an apparent activation energy barrier for self-diffusion, $E_{a}$ $=1.4 \mathrm{eV}$ and a pre-factor $D_{0}=1.0 \cdot 10^{-6} \mathrm{~cm}^{2} / \mathrm{s}$. By using these new values, $X_{p}$ was again calculated (eq. 2 ) and compared to the measured $X_{p}$ in Figure 3 (black line). It should be noted that eq. 2 assumes isothermal conditions, and that the comparison with the experimental data obtained during constant temperature ramping therefore has to assume that the temperature steps are small enough to approximate intervals with constant temperatures. Despite this precaution, we notice the surprisingly good agreement between the experiment and the relatively simple model, which as mentioned, does not take possible effects of the gas environment, degree of wetting and the support material into account. In addition, both models presented by Figure $1 \mathrm{~b}$ were re-calculated by using the new values for $E_{a}$ and $D_{0}$ and the result is presented as lines in Figure $3 \mathrm{~b}$. In this figure the models describe the temperature ranges where Pt nanoparticles with diameters $=3 \mathrm{~nm}$ are expected to migrate (blue line) and coalesce (red lines) on a time scale of minutes. We notice that the temperatures where the simple models predict migration and coalescence are consistent with the temperatures where we observed coarsening events due to migration and coalescence (blue) or just coalescence (red). It should for example be noticed that coalescence is observed at the temperatures predicted by this model. The observed onset temperature for coarsening of agglomerated $\mathrm{Pt}$ in $\mathrm{H}_{2}$ around $200^{\circ} \mathrm{C}$ (Figure $3 \mathrm{~b}$ ) is also consistent with early studies of agglomerated Pt (so-called platinum-black) in $\mathrm{H}_{2}$ where coarsening is clearly observed at $350{ }^{\circ} \mathrm{C}$ and signs of sintering is observed already at $200{ }^{\circ} \mathrm{C}[46,47]$. 
For supported Pt nanoparticles in $\mathrm{H}_{2}$, the reported onset temperature for coarsening varies in different studies. In an early study from Fiedorow et al. an onset temperature of ca. $600{ }^{\circ} \mathrm{C}$ was determined by chemisorption for a commercial $\mathrm{Pt} / \mathrm{Al}_{2} \mathrm{O}_{3}$ catalyst in $\mathrm{H}_{2}$ [21]. For a different $\mathrm{Pt} / \mathrm{Al}_{2} \mathrm{O}_{3}$ catalyst with a higher dispersion the same study reports a higher onset temperature for Pt coarsening of ca. $700{ }^{\circ} \mathrm{C}$. At first sight, this result may seem surprising since a higher dispersion indicates a smaller mean Pt particle size which should increase $X_{p}$ (Figure 1a). The results in the present study, however, suggest a simple explanation for this apparent discrepancy. Figure $3 \mathrm{~b}$ shows that separated Pt nanoparticles are more stable than agglomerated ones. A catalyst for which the ratio separated/agglomerated Pt nanoparticles is high, will therefore both be more stable and have a higher dispersion than a catalyst with a lower ratio. So generally, high dispersions achieved by separating the Pt particles should lead to high stability for supported Pt nanoparticles in $\mathrm{H}_{2}$.

In a recent study by Matos et al. EXAFS results show that well-dispersed Pt nanoparticles on a $\gamma-\mathrm{Al}_{2} \mathrm{O}_{3}$ surface are stable in $\mathrm{H}_{2}$ at $650{ }^{\circ} \mathrm{C}$, but coarsen at $800{ }^{\circ} \mathrm{C}$ [26]. Another recent study by Li et al, reports $3 \mathrm{~nm}$ sized $\mathrm{Pt}$ nanoparticles supported on zeolite (ZSM-5) to be stable in $\mathrm{H}_{2}$ at $750{ }^{\circ} \mathrm{C}$ [48]. These findings are in agreement with the present observations for separated Pt nanoparticles (Figure 3b). The study by Matos et al. also shows that a pre-treatment of their $\mathrm{Pt} / \mathrm{Al}_{2} \mathrm{O}_{3}$ catalyst at $450{ }^{\circ} \mathrm{C}$ in oxygen can increase the $\mathrm{Pt}$ nanoparticle stability during treatment in $\mathrm{H}_{2}$ at $800{ }^{\circ} \mathrm{C}$. In oxygen, the coarsening of supported Pt nanoparticles is fully dominated by Ostwald ripening [22,23], contrary to the migration and coalescence mechanism found in the present study for $\mathrm{H}_{2}$. It is often suggested that atomic Pt-oxygen species are more volatile than pure Pt atoms and that they can be distributed over the support by add-atom migration. This has been used as an explanation for the often reported re-dispersion of supported nanoparticles Pt nanoparticles when treated in oxygen at temperatures around $500{ }^{\circ} \mathrm{C}$ $[5,16,18,19,49,50]$. In the light of the present results /we can explain the stabilizing effect of the pre-treatment in oxygen reported by Matos et. al [26]: increasing the dispersion of the Pt in oxygen leads to an increase in the ratio separated/agglomerated $\mathrm{Pt}$ and thereby increase the overall stability.

Since it is well-known that the type of support can influence nanoparticle coarsening [6,16,51-53] a few comments should be added regarding the carbon support. Specifically, the stability of the support itself is here considered. Pure CB is reported to be stable at higher temperatures than the maximum of the current experiment although surface complexes decompose at temperatures above ca. $200{ }^{\circ} \mathrm{C}$ [54]. Despite this, morphology changes in the CB support can be observed (Figure 2). These observations can, at least partly, be explained by rotational and translational movements induced by the coarsening dynamics of the agglomerated Pt. However, it cannot be excluded that the observed changes in CB morphology, in particular that the highest temperatures (Figure 2h-i), is also due to changes within the structure of the primary CB particles. Such changes could also influence the observed Pt nanoparticle coarsening.

The present in situ coarsening experiment covers a relatively broad range of temperatures from $50{ }^{\circ} \mathrm{C}$ to almost $1000^{\circ} \mathrm{C}$ and can therefore have relevance for various $\mathrm{Pt}$ nanoparticle applications. On the other hand, the ramping rate of $10{ }^{\circ} \mathrm{C} / \mathrm{min}$ gives the $\mathrm{Pt} / \mathrm{CB}$ system short time at each temperature when considering that nanoparticle coarsening is usually a long term degradation mechanism. The focus of the present work is therefore not to predict the coarsening behavior of carbon supported Pt catalysts at the specific practical operation conditions, but to determine the coarsening mechanism of supported Pt in hydrogen. The results show that simple models give good descriptions of the observed coarsening behavior, which paves a way to predict Pt coarsening over longer time scales at the relevant temperature.

That the particle migration mechanism is dominating for supported Pt nanoparticles in $\mathrm{H}_{2}$ can be good news for researchers working on stabilizing supported Pt nanoparticles. For example it has been suggested that nanoparticles can be stabilized by encapsulation in zeolites with channels that allow for gas diffusion, but not for 
transporting the entire nanoparticles [55]. Ostwald ripening cannot be completely hindered by this concept because the migrating atomic species have sizes comparable to the gas molecules, but the concept could efficiently inhibit Pt coarsening via particle migration. The approach has already been reported to show promising results for Pt nanoparticles [48] in zeolites and Pt alloy nanoparticles in silica [15].

\section{Conclusions}

The coarsening of two types of CB supported Pt nanoparticles: separated and agglomerated was observed during the exposure to $\mathrm{H}_{2} / \mathrm{Ar}$ at constant temperature ramping up to $960{ }^{\circ} \mathrm{C}$. The separated $\mathrm{Pt}$ nanoparticles were stable up to ca. $800{ }^{\circ} \mathrm{C}$ at a heating rate of $10{ }^{\circ} \mathrm{C} / \mathrm{min}$ and the coarsening at higher temperatures was dominated by the particle migration and coalescence mechanism. The agglomerated Pt nanoparticles coarsened already above 200 ${ }^{\circ} \mathrm{C}$ and this coarsening was dominated by coalescence without migration. The results show that separation of $\mathrm{Pt}$ nanoparticles is an efficient route for stabilizing supported Pt nanoparticles in a hydrogen environment. The temperature-dependency of the observed particle sizes and migration distances was found to be consistent with simple models for the migration and coalescence.

\section{Acknowledgements}

The authors thank the Danish ForskEL program (SMARTMEA) and H.C Ørsted Postdoc Fellowship for providing funding. The A.P. Møller and Christine Mc-Kinney Møller Foundation are gratefully acknowledged for their contribution toward the establishment of the Center for Electron Nanoscopy in the Technical University of Denmark. Yan Wang is financed by the Priority Academic Program Development of Jiangsu Higher Education Institutions.

\section{References}

[1] Li Y and Somorjai G A 2010 Nanoscale advances in catalysis and energy applications Nano Lett. 10 2289-95

[2] Bell A T, Bond G C, Thompson D T, Valden M, Lai X, Goodman D W, Blasko T, Nieto J M L, Chen K, Bell A T, Iglesia E, Koyama T, Komaya T, Gai P L, Weyland M, Durscher G, Browning N D, Pennycook S J, Besenbacker F, Thune P C, Loss J, Wonter D, Leustra P J, Niemantsverdriet J W, Corker J, Vidal V, Theolier A, Thivolle-Cazat J, Basset J-M, Nozkaki C, Lugmair C G, Bell A T, Tilley T D, Kolb D, Jong K P De and Geus J W 2003 The impact of nanoscience on heterogeneous catalysis. Science 299 1688-91

[3] Chen S-J, Chien F C, Lin G Y and Lee K C 2004 Enhancement of the resolution of surface plasmon resonance biosensors by control of the size and distribution of nanoparticles Opt. Lett. 29 1390-2

[4] Wang W, Wang Z, Wang J, Zhong C and Liu C 2017 Highly Active and Stable Pt - Pd Alloy Catalysts Synthesized by Room-Temperature Electron Reduction for Oxygen Reduction Reaction Adv. Sci. 1600486

[5] Bartholomew CH 1993 Model Catalyst Studies of Supported Metal Sintering and Redispersion Kinetics Catalysis - A specialist Periodical Report pp 41-82

[6] Wynblatt P and Gjostein N A 1976 Supported Metal Crystallites Prog. Solid State Chem. 9 21-58

[7] Cattaneo F, Germagnoli E and Grasso F 1962 Self-diffusion in Platinum Proceedings of the Physical Society. Section B pp 1373-83

[8] Kyuno K and Ehrlich G 1999 Diffusion and dissociation of platinum clusters on Pt(111) Surf. Sci. 437 $29-37$ 
[9] Prestat E, Popescu R, Blank H, Schneider R and Gerthsen D 2013 Coarsening of Pt nanoparticles on amorphous carbon film Surf. Sci. 609 195-202

[10] Schneider S, Surrey A, Pohl D, Schultz L and Rellinghaus B 2014 Atomic surface diffusion on Pt nanoparticles quantified by high-resolution transmission electron microscopy Micron 63 52-6

[11] Yang J, Hu W, Yi G and Tang J 2007 Atomistic simulation of Pt trimer on Pt(1 11 1) surface Appl. Surf. Sci. 253 8825-9

[12] McLean M and Hondros E D 1971 A Study of Grain-Boundary Grooving at the Platinum / Alumina Interface J. Mater. Sci. 6 19-24

[13] Zhou Y and Xu Q J 2013 A Review of Pt-Based Anode Catalysts Preparation for Direct Ethanol Fuel Cell Adv. Mater. Res. 860-863 797-800

[14] Chebbi R, Wan Daud W R, Mohamad A B and Kadhum A A H 2011 Review of Parameters Affecting Performance of (Pt/C) Electrode for Proton Exchange Membrane Fuel Cells (Pemfcs) Adv. Mater. Res. 233-235 43-9

[15] Oh J-G, Oh H-S, Lee W H and Kim H 2012 Preparation of carbon-supported nanosegregated Pt alloy catalysts for the oxygen reduction reaction using a silica encapsulation process to inhibit the sintering effect during heat treatment J. Mater. Chem. 22 15215-20

[16] Bartholomew C H 1993 Sintering kinetics of supported metals: New perspectives from a unifying GPLE treatment Appl. Catal. A Gen. 107 1-57

[17] Harris P J F 1995 Growth and structure of supported metal catalyst particles Int. Mater. Rev. 40 97-115

[18] Flynn P and Wanke S E 1975 Experimental studies of sintering of supported platinum catalysts J. Catal. 37 432-48

[19] Lee T and Kim Y G 1984 Redispersion of supported platinum catalysts J. Catal. 90 279-91

[20] Flynn P C and Wanke S E 1974 A Model of Supported Metal Catalyst Sintering II. Application of Model J. Catal. 34 400-10

[21] Fiedorow R M J, Chahar B S and Wanke S E 1978 The sintering of supported metal catalysts. II. Comparison of sintering rates of supported $\mathrm{Pt}$, Ir, and Rh catalysts in hydrogen and oxygen J. Catal. 51 193-202

[22] Simonsen S B, Chorkendorff I, Dahl S, Skoglundh M, Sehested J and Helveg S 2010 Direct observations of oxygen-induced platinum nanoparticle ripening studied by in situ TEM J. Am. Chem. Soc. 132 7968-75

[23] Simonsen S B, Chorkendorff I, Dahl S, Skoglundh M, Sehested J and Helveg S 2011 Ostwald ripening in a Pt/SiO2 model catalyst studied by in situ TEM J. Catal. 281 147-55

[24] Lööf P, Stenbom B, Nordén H and Kasemo B 1993 Rapid Sintering in NO of Nanometre-Sized Pt Particles on gamma-Al2O3 Oberved by CO Temperature-Programmed Desorption and Transmission Electron Microscopy J. Catal. 144 60-76

[25] Horch S and Lorensen H T 1999 Enhancement of surface self-diffusion of platinum atoms by adsorbed hydrogen. Nature 398 134-6

[26] Matos J, Ono L K, Behafarid F, Croy J R, Mostafa S, DeLaRiva a. T, Datye a. K, Frenkel a. I and Roldan Cuenya B 2012 In situ coarsening study of inverse micelle-prepared Pt nanoparticles supported on

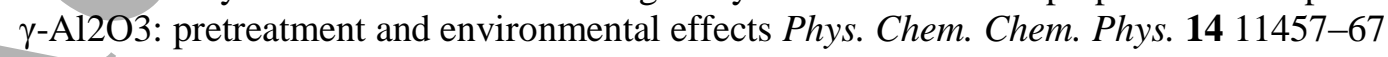


[27] Glassl H, Kramer R and Hayek K 1981 Electron Microscopy of Pt/Al2O3 Model Catalysts. II. Sintering in Atmospheres of H2, O2 and Ar J. Catal. 396 388-96

[28] Lifshitz I M and Slyozov V V 1961 The kinetics of precipitation from supersaturated solid solutions $J$. Phys. Chem. Solids $1935-50$

[29] Wagner C Z 1961 Theorie der alterung von niederschlagen durch umlosen (Ostwald-reifung) Zeitschrift für Electrochem. 65 581-91

[30] Granqvist C G and Buhrman R A 1976 Size Distributions for Supported Metal Catalysts - Coalescence Growth versus Ostwald Ripening J. Catal. 42 477-9

[31] Wanke S E 1977 Comments on the sintering Mechanims of Supported Metal Catalysts 46 234-7

[32] Datye A K, Xu Q, Kharas K C and McCarty J M 2006 Particle size distributions in heterogeneous catalysts: What do they tell us about the sintering mechanism? Catal. Today 111 59-67

[33] Simonsen S B, Chorkendorff I, Dahl S, Skoglundh M, Meinander K, Jensen T N, Lauritsen J V and Helveg S 2012 Effect of particle morphology on the ripening of supported Pt nanoparticles J. Phys. Chem. C $1165646-53$

[34] Morgenstern K, Rosenfeld G and Comsa G 1999 Local correlation during Ostwald ripening of twodimensional islands on $\operatorname{Ag}(111)$ Surf. Sci. 441 289-300

[35] Jak M J J, Konstapel C, van Kreuningen A, Verhoeven J and Freńken J W M 2000 Scanning tunnelling microscopy study of the growth of small palladium particles on TiO2(110) Surf. Sci. 457 295-310

[36] Yang F, Chen M S and Goodman D W 2009 Sintering of Au particles supported on TiO 2(110) during CO oxidation J. Phys. Chem. C 113 254-60

[37] Bartelt N C, Theis W and Tromp R 1996 Ostwald ripening of two-dimensional islands on Si(001) Phys. Rev. B 54 11741-51

[38] Baker R T K, Harris P S and Thomas R B 1974 Direct observation of particle mobility on a surface in a gaseous environment Surf. Sci. 46 311-6

[39] Heinemann K and Poppa H 1976 Direct observation of small cluster mobility and ripening Thin Solid Films 33 237-51

[40] Anton R and Kreutzer P 2000 In situ TEM evaluation of the growth kinetics of Au particles on highly oriented pyrolithic graphite at elevated temperatures Phys. Rev. B 61 16077-83

[41] Liu R J, Crozier P A, Smith C M, Hucul D A, Blackson J and Salaita G 2005 Metal sintering mechanisms and regeneration of palladium/alumina hydrogenation catalysts Appl. Catal. A Gen. 282 111-21

[42] Williamson M J, Tromp R M, Vereecken P M, Hull R and Ross F M 2003 Dynamic microscopy of nanoscale cluster growth at the solid-liquid interface. Nat. Mater. $2532-6$

[43] Walsh M J, Yoshida K, Gai P L and Boyes E D 2009 In-situ heating studies of gold nanoparticles in an aberration corrected transmission electron microscope J. Phys. Conf. Ser. 24112058

[44] Hansen T W and Wagner J B 2014 Catalysts under Controlled Atmospheres in the Transmission Electron Microscope ACS Catal. 4 1673-85

[45] Zheng H M, Smith R K, Jun Y W, Kisielowski C, Dahmen U and Alivisatos A P 2009 Observation of Single Colloidal Platinum Nanocrystal Growth Trajectories Science 324 1309-12 
[46] Paál Z, Zimmer H, Günter J R, Schlögl R and Muhler M 1989 Sintering of platinum-black in hydrogen: Morphology and catalytic activity J. Catal. 119 146-60

[47] Paál Z, Zimmer H and Günter J R 1989 Effect of Hydrogen on the Sintering of Pt-Black Catalyst and on its Activity in Skeletal Hydrocarbon Reactions Zeitschrift für Phys. Chemie Neue Folge 164 1135-44

[48] Li S, Tuel A, Meunier F, Aouine M and Farrusseng D 2015 Platinum nanoparticles entrapped in zeolite nanoshells as active and sintering-resistant arene hydrogenation catalysts J. Catal. 332 25-30

[49] Ruckenstein E and Chu Y F 1979 Redispersion of platinum crystallites supported on alumina - Role of wetting J. Catal. 59109

[50] Rickard J M, Genovese L, Moata A and Nitsche S 1990 Redispersion of Platinum on Pt/A12O3 Model Catalyst in Oxygen Studied by Transmission Electron Microscopy J. Catal. 121 141-52

[51] McVicker G B, Garten R L and Baker R T K 1978 Surface area stabilization of Ir-Al2O3 catalysts by $\mathrm{CaO}, \mathrm{SrO}$ and $\mathrm{BaO}$ under oxygen atmospheres: Implications on the Mechanism of Catalyst Sintering and Redispersion J. Catal 54 129-42

[52] Chen M and Schmidt L D 1978 Morphology and sintering of Pt crystallites on amorphous SiO2 J. Catal. $55348-60$

[53] Tanabe T, Nagai Y, Dohmae K, Sobukawa H and Shinjoh H 2008 Sintering and redispersion behavior of Pt on Pt/MgO J. Catal. 257 117-24

[54] Puri B R and Bansal R C 1964 Studies in Surface Chemistry of Carbon Blacks Part I . High Temperature Evacuation Carbon N. Y. $1451-5$

[55] Laursen A B, Højholt K T, Lundegaard L F, Simonsen S B, Helveg S, Schüth F, Paul M, Grunwaldt J D, Kegnœs S, Christensen C H and Egeblad K 2010 Substrate size-selective catalysis with zeoliteencapsulated gold nanoparticles Angew. Chemie - Int. Ed. 49 3504-7

\section{Graphical abstract}


Movie presenting an in situ TEM image series of Pt nanoparticles on carbon black support during temperature ramping at $10^{\circ} \mathrm{C} / \mathrm{min}$ and exposure of $6 \mathrm{mbar} 20 \% \mathrm{H}_{2} / \mathrm{Ar}$. Temperatures are indicated at the images in the movie.

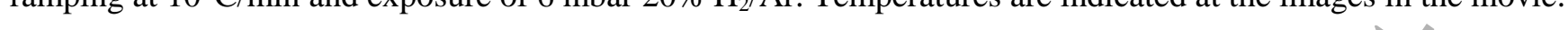

